\title{
Acción de cepas nativas de Bacillus thuringiensis (Berliner), como control biológico de Spodoptera frugiperda (J.E. Smith). Lepidoptera: Noctuidae
}

\section{Action of Bacillus thuringiensis (Berliner), as biological control of Spodoptera frugiperda (J.E. Smith). Lepidoptera: Noctuidae}

\author{
Jorge E. Díaz* \\ Recibido para publicación: Abril 23 de 2016 - Aceptado para publicación: Octubre 13 de 2016
}

\begin{abstract}
RESUMEN
Se evaluó la actividad insecticida de las cepas M3001, M3003, M3004, M3007, M3008, M4001, M2006, M5002, M5004 y M28005 de Bacillus thuringiensis Bt. contra Spodoptera frugiperda las cuales provienen de suelos de Funza y Silvania (Cundinamarca) Tunja (Boyacá) en cultivos de fríjol, arveja, maíz y naranja, comparadas con un testigo comercial HD1 (Subsp. Kurstaki), contra $S$. frugiperda. Se determinó la $\mathrm{CL}_{50}$ por el método "PROBIT", la cual fue de 5.88 E-4 mg de i.a/ $\mathrm{ml}$ de dieta, de la cepa HD1 con diferentes dosis $(0,0$; 6,8 E-2; 3,4E-2; 6,8E-3; 6,8E-4; 6,8E-5 y 6,8E-6 mg de i.a/ml de dieta) en larvas de $S$. frugiperda. Evaluando la mortalidad a las 96 y 120 horas; posteriormente la concentración letal media $\left(\mathrm{CL}_{50}\right)$ determinada con la cepa HD1 se procedió a utilizar esta concentración en cada uno de los aislamientos nativos de $B$. thuringiensis para ser comparada con la $\mathrm{CL}_{50}$ del testigo comercial. Se empleó diseño completamente al azar, con siete tratamientos (cada uno con 25 larvas de primer instar) y tres repeticiones. Para el segundo ensayo de la determinación de aislamientos promisorios de $\mathrm{Bt}$, se arregló un diseño completamente al azar, con 11 tratamientos (cada uno con 20 larvas de primer instar) y 3 replicaciones. Los resultados indicaron que los aislamientos M3008 y M4001 presentaron mayores promedios de mortalidad, de $75 \%$ y $71,65 \%$ respectivamente, en las larvas en dieta purificada, comparada con la mortalidad de la $\mathrm{CL}_{50}$ del testigo comercial.
\end{abstract}

Palabras Clave: Bioensayo, Hongos, larvas, entomopatógeno, mortalidad.

\begin{abstract}
This research evaluated the insecticidal activity of various native isolates of Bacillus thuringiensis against Spodoptera frugiperda, From Soils of Funza and Silvania (Cundinamarca) Tunja (Boyacá) in crops of beans, peas, maize and orange compared with a commercial witness HD1 (subsp. Kurstaki) against $S$. frugiperda. $\mathrm{LC}_{50}$ lethal concentration average was initially determined by the "probit" method, which was $5.88 \mathrm{E}-4 \mathrm{mg}$ ai / $\mathrm{ml}$ of diet, strain HD1 with different doses $(0.0 ; 6.8 \mathrm{E}-2 ; 3.4 \mathrm{E}-2$; $6.8 \mathrm{E}-3 ; 6.8 \mathrm{E}-4 ; 6.8 \mathrm{E}-5$ 6.8E-6 and ai $\mathrm{mg} / \mathrm{ml}$ diet) in first instar larvae $S$. frugiperda. In addition to qualitative observations mortality was measured at 96 and 120 hours. Subsequently the determined median lethal concentration $\left(\mathrm{LC}_{50}\right)$ with strain $\mathrm{HD} 1$ proceeded to use this concentration in each native $B$. thuringiensis isolates to be compared with the commercial control $\mathrm{CL}_{50}$. Design was completely randomized with 7 treatments (each with 25 first instar larvae) and 3 replications. For the second test determining promissory isolates of $\mathrm{Bt}$, a completely randomized design with 11 treatments (each with 20 first instar larvae) and 3 replications was arranged. Results indicated that M3008 and M4001 native isolates have higher mortality averages, which were $75 \%$ and $71.65 \%$ respectively in first instar larvae in purified diet, compared with mortality $\mathrm{LC}_{50}$ of commercial control.
\end{abstract}

Key words: Bioassay, fungi, larvae, entomopathogenic, mortality.

\footnotetext{
1* M.Sc. Docente de Matemáticas. I.E. General Santander. Soacha -Cundinamarca.Colombia Cra. 68 F 64 f 49 A 402 . Celular: 3153870768. Correo: jediazp@unal.edu.co, jorgediaz333@gmail.com.
} 
Díaz, J. - Control biológico de Spodoptera frugiperda

\section{INTRODUCCIÓN}

Una de los insectos-plaga de mayor impacto económico en Colombia es el gusano cogollero del maíz, Spodoptera frugiperda (Lepidoptera: Noctuidae). Teniendo en cuenta que estas larvas logran alimentarse de 28 especies vegetales cultivadas, entre las cuales se destacan el maíz, sorgo, algodón, soya, higuerilla, tomate de huerta, caña de azúcar, ajonjolí, arroz, maní, melón y girasol. Elige para su alimentación a las gramíneas, cultivadas o no, causando mermas elevadas a los cultivos, ante todo, cuando sus poblaciones logran altos niveles durante las épocas de verano (Fernández 2002).

Al presente una de las formas más frecuentes de controlar plagas en los disímiles cultivos se realiza mediante el uso de agroquímicos; practica que ha permitido conservar poblaciones de plagas en niveles permisibles y disminuir el daño que reducen el rendimiento del cultivo. No obstante el uso indistinto ha generado problemas de contaminación del suelo y fuentes hídricas. Asimismo, se eliminan los enemigos naturales de insectos y hongos secundarios que ante la desaparición de sus reguladores naturales pueden convertirse en plagas de valor económico (Quintero 2015).

En nuestro país, no existen estadísticas concernientes a pérdidas confiables ocasionadas por el insecto, pero en el cultivo de maíz tecnificado, se discurre que un 5,6\% a un $10 \%$ de los costos de producción pertenecen al control químico de la plaga (URPA, citado por Polania et al. 2009).

"Una de las alternativas frente al control de Spodoptera frugiperda es el uso de insecticidas biológicos como la bacteria Bacillus thuringiensis y los virus entomopatógenos como los Baculovirus" (Quintero 2015). Los baculovirus se han tratado de manera extensiva para el control biológico de disímiles plagas del orden lepidóptera a nivel cosmopolita
(Szewczyk et al. 2011), con excelentes resultados.

\section{MATERIALES Y MÉTODOS}

Esta investigación se realizó en las instalaciones del insectario del Instituto de Biotecnología, y en el laboratorio de control biológico de la Facultad de Ingeniería Agronómica de la Universidad Nacional de Colombia sede Bogotá. La temperatura promedio interna del laboratorio fue de $27 \pm 5{ }^{\circ} \mathrm{C}$, humedad relativa de $75 \pm 5 \%$ y un fotoperiodo de 12:12 Horas (Luz-Oscuridad). La cepa y los aislamientos de Bacillus thuringiensis fueron cultivados $y$ fermentados en el Instituto de Biotecnología de la Universidad Nacional de Colombia (Tabla 1).

Tabla 1. Aislamientos de Bacillus thuringiensis.

\begin{tabular}{cc}
\hline Tratamientos & AISLAMIENTO \\
\hline T1 & M3001 \\
T2 & M3003 \\
T3 & M3004 \\
T4 & M3007 \\
T5 & M3008 \\
T6 & M2006 \\
T7 & M4001 \\
T8 & M5002 \\
T9 & M5004 \\
T10 & M28005 \\
T11 & HD1 \\
\hline
\end{tabular}

Para la investigación se consideraron una cepa comercial (HD1), 10 aislamientos nativos de un organismo patógeno y uno de su hospedero, las cuales presentan las siguientes características:

Se recolecto una raza de $S$. frugiperda en un cultivo de sorgo de la zona del Espinal (Tolima). Para ello se procedió a la recolección de larvas de todos los instares, en campo. Se realizó la cría masiva de $S$. frugiperda, posteriormente las larvas de primer instar fueron llevadas a copas plásticas con 1,35 ml de dieta y su respectiva dosis de $B$. thuringiensis. Estas fueron seleccionadas por el Instituto de Biotecnología 
de acuerdo a la concentración de proteína que produzcan y su posible espectro de acción comparada con la cepa comercial HD1.

\section{Determinación de la actividad insecticida} de los 10 aislamientos nativos de Bacillus thuringiensis con relación al estándar hd1. Después de obtener la $\mathrm{CL}_{50}$ de la cepa comercial HD1, se utilizó esta concentración expresada en i.a. para cada uno de los 10 aislamientos nativos de B.thuringiensis.

Para cada aislamiento a probar se suspendió en el agua que se agrega a la licuadora en el momento de preparar la dieta, luego de licuada la dieta se vertió $2 \mathrm{ml}$ por vaso plástico; posteriormente cuando se gelificó se colocó una larva de primer instar por copa utilizando un pincel; por cada aislamiento se utilizó una dosis con tres unidades experimentales, cada una de ellas con 20 larvas colocadas individualmente para un total de 60 larvas por aislamiento incluyendo al testigo absoluto. En total se utilizaron 780 larvas de primer instar para el segundo ensayo.

Prueba de efectividad. Estas se realizaron con el fin de determinar si la muerte del insecto fue causada por la bacteria o por un factor externo a esta como manipulación, inapetencia u otros organismos. Para esta se colectaron larvas muertas en las diferentes dosis y aislamientos, se les agregó agua y con la ayuda de un vortex se hizo una suspensión homogénea de la cual se sacó parte para realizar un cultivo en agar nutritivo y comprobar que efectivamente la bacteria fue ingerida por el insecto; de la otra parte se tomó una gota para montarla en una lámina porta-objeto y hacer observaciones al microscopio, para distinguir fauna.

\section{RESULTADOS Y DISCUSIÓN}

La caracterización de cada aislamiento nativo se puede observar en la tabla 2.

De Producción: Para la fermentación de las cepas de $B$. thuringiensis se utilizó caldo nutritivo (HCO); este proceso se llevó a cabo a $29{ }^{\circ} \mathrm{C}$ y $200 \mathrm{rpm}$. Después de la fermentación se determinó la cantidad de ingrediente activo por la técnica de LOWRY, centrifugando a 4000 rpm por 15 minutos a $4{ }^{\circ} \mathrm{C}$ en un equipo Survall RC-3B (Tabla 2).

\section{Determinación de rangos de mortalidad para el} testigo comercial hd1. Con el fin de establecer parámetros de evaluación y comparación con aislamientos a ensayar, como cantidad de dosis a usar, metodología para realizar la lectura de mortandad y otros, se procedió a determinar los parámetros con la cepa comercial en dieta purificada (Tabla 3).

Tabla 2. Características del cristal, bacilo, prueba de electroforesis, inmunodetección (Elisa) de cada uno de los aislamientos de Bacillus thurigiensis evaluados.

\begin{tabular}{lllcl}
\hline MUESTRA & \multicolumn{1}{c}{ CRISTAL } & \multicolumn{1}{c}{ BACILO } & ELECTROFORESIS & ELISA \\
\hline M2006 & Rómbico & Encadenados alargados & $130-70$ & Cry I \\
M3001 & Rómbico y Esférico & Encadenados alargados & $130-70$ & Cry I \\
M3003 & Rómbico y Esférico & Encadenados alargados & $130-70$ & Cry I \\
M3004 & Rómbico y Esférico & Encadenados alargados & $130-70$ & Cry I \\
M3007 & Rómbico y Esférico & Encadenados alargados & $130-70$ & Cry I \\
M3008 & Rómbico y Bipiramidal & Grandes encadenados & $130-70$ & Cry I \\
M4001 & Rómbico & Encadenados delgados & $130-70$ & Cry I \\
M5002 & Rómbico & Encadenados delgados & $130-70$ & Cry I \\
M5004 & Rómbico y Bipiramidal & Encadenados delgados & $130-70$ & Cry I \\
M28005 & Rómbico & Encadenados & $130-70$ & Cry I \\
\hline
\end{tabular}


Tabla 3. Tratamientos con Bacillus thuringiensis realizados bajo condiciones de laboratorio sobre larvas de primer instar de $S$. frugiperda. Para determinar la $\mathrm{CL}_{50}$

\begin{tabular}{cc}
\hline TRATAMIENTO & DOSIS $\left(\mathbf{m g} \mathbf{~ m l}^{-1} \mathbf{~ d e ~ B t )}\right.$ \\
\hline T0 & 0,0 \\
T1 & $6,8 \mathrm{E}^{-2}$ \\
T2 & $3,4 \mathrm{E}^{-2}$ \\
T3 & $6,8 \mathrm{E}^{-3}$ \\
T4 & $6,8 \mathrm{E}$ \\
T5 & $6,8 \mathrm{E}$ \\
T6 & $6,8 \mathrm{E}$ \\
\hline
\end{tabular}

Considerando el resultado anterior, se procedió al análisis de regresión "Método Probit" para el instar estudiado, utilizando los datos de mortalidad originales. La salida del análisis de regresión "Método Probit", mediante el paquete estadístico SAS, en los cuales se indica el intercepto y su pendiente, dando como ecuación la siguiente:

$Y=7,032+0,629$

Cálculo matemático de la concentración letal media. Con base en la ecuación de regresión "Probit" hacemos $\mathrm{Y}=5$ (valor Probit correspondiente al $50 \%$ de la variable dependiente mortalidad) y obtenemos el valor de $X$ (variable independiente), a este valor se le halla el antilogaritmo y obtenemos el valor real de la $\mathrm{CL}_{50}$ expresada en miligramos de ingrediente activo por mililitro de dieta purificada.

$Y=7,032+0,629 X$

$\mathrm{Y}=5$

$X=5-7,032 / 0,629$

$X=-3,230$

Ahora Antilogaritmo de -3,230

Obtenemos: CL50 = 5,88 x 10 $(\mathrm{mg} \mathrm{ml}-1 \mathrm{de}$ dieta)
El análisis de la concentración letal media, el límite de confianza y pendientes de la línea de regresión para condiciones de laboratorio no mostró diferencias significativas entre las replicaciones del bioensayo, por presentarse en todos los casos sobrexposición de los límites de confianza del 95\% (Tabashnik 1990).

\section{Mortalidad en la Determinación de la $\mathrm{CL}_{50}$} de $B$. thuringiensis. En primer instar larval de $\boldsymbol{S}$. frugiperda. En la ecuación de regresión obtenida para el tiempo de evaluación de 120 horas, se sustituyó los valores de X por el logaritmo de las concentraciones que se usaron en el experimento (Tabla 4).

Tabla 4. Porcentaje de mortalidad de aislamientos nativos de $B$. thuriengiensis. En dieta purificada, en larvas de primer instar de $S$. frugiperda a las 120 horas.

\begin{tabular}{cc}
\hline AISLAMIENTOS & MORTALIDAD (\%) \\
\hline M2006 & 23,30 \\
M3001 & 43,30 \\
M3003 & 26,50 \\
M3004 & 30,00 \\
M3007 & 40,00 \\
M3008 & 75,00 \\
M4001 & 71,65 \\
M5002 & 36,65 \\
M5004 & 21,65 \\
M28005 & 30,00 \\
\hline
\end{tabular}

* Concentración: 5,88 x 10 mg/ml de dieta $=3,25 \mu \mathrm{g} / \mathrm{cm}^{2}$

Diseño experimental. Para el primer ensayo de la determinación de $\mathrm{CL}_{50}$ se utilizó un diseño completamente al azar, con 7 tratamientos (cada uno con 25 larvas de primer instar) y 3 replicaciones. Para el segundo ensayo de la determinación de aislamientos promisorios de Bt, se arregló un diseño completamente al azar, con 11 tratamientos (cada uno con 20 larvas de primer instar) y 3 replicaciones.

Con el dato de mortalidad obtenido a las 120 horas, en condiciones de laboratorio 
y previamente hecha la transformación de éstas mediante la fórmula $\mathrm{y}=$ arcoseno $\sqrt{ } \mathrm{X}$. Los resultados del ensayo, fueron sometidos a un análisis de varianza con el procedimiento análisis de varianza del software estadístico SPSS versión 23. Con un nivel de significación del 5\%, obteniéndose el siguiente resultado: $\mathrm{Ho}=\mu \mathrm{i}=\mu$ para todo $\mathrm{i} \mathrm{H} 1=\mu \mathrm{i} \neq \mu$ para al menos algún i. La significancia de los tratamientos es 0,001 menor al valor de alfa de 0,05, por tanto se rechaza la hipótesis nula $(\mathrm{Ho})$ de igualdad entre tratamientos, y del cual se puede concluir que los tratamientos discriminados en dosis presentan diferencias altamente significativas entre sí. El coeficiente de variación obtenido fue de $14,81 \%$ lo cual concuerda con lo reportado por Dulmage et al. Citado por (Gallegos 1990), donde menciona que para validar un bioensayo el coeficiente de variación debe ser menos o igual al $20 \%$.

Con la concentración letal media para larvas de primer instar de S.frugiperda con la cepa HD1 de B.thuringiensis la cual fue de 3,25 $\mu \mathrm{g} \mathrm{cm}^{2}$, que comparado con los resultados obtenidos por (Del Rincón et al. 2006), para tres cepas nativas de B.thuringiensis se estimaron valores de $\mathrm{CL}_{50}$

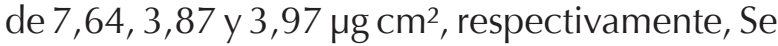
presentó un nivel menor de $\mathrm{CL}_{50}$. Esto se puede evidenciar por lo corroborado por (LópezEdwards et al. 1999) quienes encontraron, que las larvas de S.frugiperda tienen diferente grado de susceptibilidad a $B$. thuringiensis, relacionado con la ubicación geográfica del insecto.

Además (Hernández 1988), menciona que las larvas de S.frugiperda, presentan susceptibilidad diferente a B.thuringiensis, relacionado a la especie o subespecie que se utilice en el control biológico.

Es transcendental resaltar que la susceptibilidad de una especie de lepidóptero a las toxinas de $B$. thuringiensis, obedece directamente al tipo de toxinas que contenga cada cepa, ya que se conoce que existe una enorme variedad de proteínas Cry, con más de 250 diferentes genes que las codifican (Crickmore et al. 1998), citado por (Del Rincón et al. 2006).

Es importante destacar que la cepa nativa (M3008), fue la más tóxica de las diez estudiadas, de modo que sería importante continuar con una identificación a nivel molecular de su contenido de genes Cry, como ya se ha realizado con anterioridad para disímiles cepas de $B$. thuringiensis por medio de la técnica del PCR (Chak et al. 1994 y Bravo et al. 1998). Las larvas de primer instar de $S$. frugiperda, se ven afectadas con el uso de toxinas de B.thuringiensis afectando su desarrollo larval y el fenómeno de alimentación, producto de la intoxicación bacteriana, tal como lo registran (Navon y Federici 1993; Stapel et al. 1998 y Flórez 2000).

\section{CONCLUSIONES}

Se determinó la concentración letal media para larvas de primer instar de $S$. frugiperda con la cepa HD1 de B.thuringiensis la cual fue de 5,88 X $10 \square \mathrm{mg} / \mathrm{ml}$ de dieta.

El desarrollo de la metodología planteada es viable de realizar para insectos que se pueden criar en condiciones de laboratorio; esta permite comparar directamente la efectividad de cepas o aislamientos nativos de B.thuringiensis a las que no se les conoce su actividad, con cepas con las que ya se les ha determinado su actividad en insectos lepidópteros. El aislamiento nativo de mejor comportamiento en dieta purificada en larvas de primer instar de $S$. frugiperda es la M3008, seguidamente del aislamiento M4001.

En lo concerniente al tiempo de evaluación del Bioensayo, se concluye que el tiempo óptimo de evaluación de los tratamientos es a las 120 horas porque en ese tiempo el porcentaje de mortalidad larval se estabiliza. 
Díaz, J. - Control biológico de Spodoptera frugiperda

\section{REFERENCIAS}

Bravo, A., Sarabia, S., Lopez, L., Ontiveros, H., Abarca, C., Ortiz, A. and Nuñez-Valdez, M. E. 1998. Characterization of cry genes in a Mexican Bacillus thuringiensis strain collection. Applied and Environmental Microbiology, 64(12), 4965-4972.

Chak, K., Chao, D., Tseng, M., Kao, S., Tuan, S. and Feng, T. 1994. Determination and distribution of cry-type genes of Bacillus thuringiensis isolates from Taiwan. Applied and environmental microbiology, 60(7), 2415-2420.

Del Rincón, M. Méndez L. e Ibarra, J. 2006. Caracterización de cepas nativas de Bacillus thuringiensis con actividad insecticida hacia el gusano cogollero del maíz Spodoptera frugiperda (lepidoptera: noctuidae).Folia Entomológica Mexicana 2006, 45 (2).

Flórez, R. 2000. Efecto de la variedad de maíz sobre el desarrollo y susceptibilidad de larvas de Spodoptera frugiperda (Lepidoptera: Noctuidae) A Bacillus thuringiensis. México. 48 p.

Gallegos, M. 1990. Implementación de la concentración mínima letal como método para cuantificar actividad de formulaciones de Bacillus thuringiensis. BIOTA, 15-23.

Hernández M. 1988. Evaluation de la Toxicité de Bacillus thuringiensis sur Spodoptera frugiperda. Entomophaga. 33(2): 163171.
López-Edwards, M., Hernández-Mendoza, A., Pescador-Rubio, J., MolinaOchoa, R., Lezama-Gutiérrez, J, Hamm, J. and Wiseman, B. 1999. Biological diferences between five populations of fall armyworm (Lepidoptera:Noctuidae) collected from corn México. Fla. Entomol. 82(2): 254-262.

Quintero, L. (2015). Uso de baculovirus como alternativa de control biológico de" $^{\prime \prime}$ Spodptera frugiperda" en el cultivo del maíz: una revisión conceptual y de avances en su aplicación.

Navon, A., Hare, J. and and Federici, B. 1993. Interactions among Heliothis virescens larvae. Cotton condensed tannin and the $\operatorname{CrylA}(\mathrm{c})$ - endotoxin of Bacillus thuringiensis. J. Chem. Ecol. 19: 24852499.

Stapel, J., Waters, D., Ruberson, J. and Lewis, W. 1998. Development and behavior of Spodoptera exigua (Lepidoptera: Noctuidae) larvae in Choice Test with Food Substrares containg toxins of Bacillus thuringiensis. Biological control. 11(1): 29-37.

Szewczyk, B., Hoyos, L., Paluszek, M., Skrzecz, I. and Lobo, M. 2006. Baculoviruses - reemerging biopesticides. Biotechnology Advances. 24: 143- 160.

Tabashnik, B. 1990. Field development of resistance to Bacillus thuriengiensis in Diamondback moth. Journal of Economic Entomology. Vol.83 (5). 1671-1676.

Polania, I., Arevalo, H. y Mejía, R. 2007. El gusano cogollero del maíz Spodoptera frugiperda (J.E. Smith) (Lepidoptera: Noctuidae) y algunas plantas transgénicas. Revista colombiana en ciencias hortícolas. 1 (1): 103 -111 